\title{
VIABILIDADE ECONÔMICA DE EMBALAGENS PARA LARANJA-DE-MESA NO ESTADO DE SÃO PAULO ${ }^{1}$
}

\author{
Lílian Maluf de Lima \\ José Vicente Caixeta Filho
}

Resumo - Este trabalho teve o objetivo principal de identificar o tipo de embalagem mais viável economicamente para laranja-de-mesa, produzida e comercializada no Estado de São Paulo. Para isso, consideraram-se três estudos de casos específicos, sob o contexto de multicasos. Buscou-se, dessa forma, determinar os custos de beneficiamento, embalagem e transporte, referentes à comercialização de laranja-de-mesa destinada a clientes como atacadistas, supermercados e centrais de abastecimento (CEASAs), a partir da unidade de beneficiamento. Os resultados para identificação da embalagem mais viável economicamente foram distintos, em razão do contexto específico de cada produtor pesquisado, ou seja, não foi possível a indicação de uma única embalagem que fosse considerada - consensualmente - como a mais adequada a todos os produtores entrevistados. Tais resultados puderam ser demonstrados a partir da utilização de uma planilha eletrônica originalmente concebida por um dos produtores visitados, a qual foi ajustada e adotada como instrumental metodológico desta pesquisa. A partir da utilização da planilha desenvolvida, produtores poderão balizar a tomada de decisões referentes à seleção de embalagens, assim como a definição do melhor preço de venda de suas frutas.

Palavras-chave: embalagem, viabilidade econômica e laranja.

Recebido em 03/01/2005 Aceito em 04/03/2005

Doutoranda em Economia Aplicada pela ESALQ/USP. E-mail: 1mlima@esalq.usp.br

Professor Titular do Departamento de Economia, Administração e Sociologia da ESALQ/USP.

E-mail: jvcaixet@esalq.usp.br 


\section{Introdução}

Os maiores avanços no desenvolvimento de embalagens ocorreram a partir da revolução industrial, em virtude da diversidade e da quantidade de bens e produtos que passaram a ser oferecidos aos consumidores. Aos poucos, a exigência com qualidade passou para o consumo de produtos in natura, dada a preocupação, por parte dos consumidores, com a origem dos alimentos (Oliveira et al., 2003).

Nesse sentido, acredita-se que o mercado interno brasileiro poderá observar um consumo crescente de produtos in natura, como frutas, se forem oferecidos com qualidade adequada, que está associada a vários aspectos relacionados com atividades de pós-colheita, dentre eles, a embalagem adotada. Cabe salientar que o volume de perdas hortifrutícolas no Brasil, durante o processo de comercialização, é extremamente alto, e grande parcela dessas perdas poderia ser evitada pela adoção de embalagens mais adequadas.

De acordo com Pichler (2003) ${ }^{4}$, o nível de perdas de hortifrutícolas durante o processo de distribuição da unidade produtora até o consumidor final varia de $30 \%$ a $40 \%$, que correspondem aos danos mecânicos decorrentes da inadequação das embalagens, condições das estradas, temperatura e nível de maturação das frutas, entre outros. Cabe ressaltar que nessas perdas se incluem as frutas que deixaram de ser consumidas, em virtude do alto preço de mercado. A CEAGESP 5 já apresenta perdas estimadas em $1,6 \%$ por mês - equivalentes aos restos de frutas, dadas as más condições de embalagens e manuseio - ocasionadas durante a comercialização nesta central. Além disso, embalagens não higienizadas propiciam o agravamento de outros problemas, como os de ordem microbiológica, que atingem não apenas a qualidade do fruto, mas também a saúde humana.

Pichler, E.F. (USP. Instituto de Pesquisas Tecnológicas, São Paulo). Comunicação pessoal, 2003.

(CEAGESP. Centro de Qualidade em Horticultura - CQH, São Paulo). Comunicação pessoal, 2003. 
No caso da laranja, a maior parte da produção brasileira ainda é comercializada em embalagens inadequadas, que prejudicam a manutenção de sua qualidade. Isso ocorre, principalmente, quando a fruta é transportada, sob essas condições, em longas distâncias, o que provoca perdas por falta de estabilidade das pilhas e pela própria abrasão. Segundo Ivancko (2002), dados do Instituto de Economia Agrícola (IEA) apontam que, em média, $30 \%$ dos produtos hortifrutícolas produzidos no Brasil não chegam a ser consumidos, contabilizando uma perda anual de US\$ 5.1 bilhões.

No que se refere às normas de embalagens, a Portaria $n^{\circ} 127$, de 4 de outubro de 1991, determinou que as frutas cítricas poderiam ser comercializadas em caixas de madeira ou papelão, ou em sacos de polietileno ou polipropileno. Dessa forma, no Entreposto Terminal de São Paulo, da Companhia de Entrepostos e Armazéns Gerais do Estado de São Paulo (CEAGESP), as laranjas costumam ser comercializadas em caixas de madeira contendo, aproximadamente, $27 \mathrm{~kg}$ de fruta. Atualmente, a Portaria $n^{\circ}$ 62, de 21 de março de 2001, mas que somente entrou em vigor em maio de 2003, estabelece a padronização e higienização de embalagens de hortifrutícolas. Logo, há forte tendência de substituição das embalagens ${ }^{6}$ de madeira tipo "M" (muito usadas para laranjas) e tipo " $\mathrm{K}$ " (muito utilizadas para tomates) por embalagens de plástico e de papelão, ou até mesmo de madeira, porém de melhor qualidade (matériaprima laminada e mais leve), conforme padrões estabelecidos pela Portaria $n^{\circ} 62$.

Assim, a higiene e a logística passam a ser então fundamentais na seleção de embalagens, incluindo os aspectos relacionados com o fato de essas embalagens serem, ou não, descartáveis, retornáveis ou paletizáveis.

Torna-se, portanto, importante a avaliação da viabilidade econômica de utilização de diferentes tipos de embalagens para laranja, incluindo a

Caixa tipo "M": caixas de madeira muito utilizadas para laranjas, com dimensões 54x29x29 cm e com capacidade para acondicionar $27 \mathrm{~kg}$. Caixa tipo "K": caixas de madeira muito utilizadas para tomates, com dimensões 49x35×22 cm e com capacidade para acondicionar $22 \mathrm{~kg}$. http://www.ceagesp.com.br 
consideração das perdas acarretadas pelo uso destas. Para isso, devese averiguar qual tipo de embalagem é mais adequado para cada tipo de produtor.

\section{Metodologia}

\subsection{Ambiente a ser estudado}

Para esclarecer qual é a embalagem mais viável economicamente sob a ótica de utilização (para cada caso estudado), tornou-se necessário um estudo dos custos, envolvidos durante seu trajeto, a partir do PackingHouse, até o varejo (supermercados, hipermercados, feiras livres e mercados), realizado por um trajeto direto, e também do Packing-House até o varejo indiretamente, passando pelo intermediário (CEASAs e CEAGESP), considerando-se, em ambos os trajetos, o custo envolvido com a perda de embalagens durante o retorno.

\subsection{Método proposto e instrumental metodológico}

Para chegar à definição de uma planilha, completa e de fácil manipulação e que também fosse capaz de demonstrar qual dos três principais tipos de embalagem (madeira, plástica e papelão) é mais viável, do ponto de vista econômico para casos específicos, foram realizadas entrevistas com três produtores representativos do setor, durante março a outubro de 2003.

A partir da resposta obtida nessas entrevistas, adotou-se então, para avaliação e análise dos objetivos deste trabalho, a planilha Fazendas Reunidas Raio de Sol (2002)7. Tal planilha, cuja estrutura se encontra reproduzida na Tabela 1 , foi considerada instrumental metodológico para

FAZENDAS REUNIDAS RAIO DE SOL. Cálculo de custos referentes à venda de laranja de mesa, em diferentes níveis de refugo e tipos de embalagens. São Carlos, 2002. 
a realização deste trabalho, considerando o total de receitas e despesas de uma carga de laranjas referente a um caminhão truck, a partir da fazenda até a unidade de beneficiamento, e desta até os seus respectivos clientes. A partir desses dados, foi realizada uma análise por meio do valor referente ao lucro (considerando-se a depreciação do maquinário de beneficiamento das frutas), obtido da utilização de cada tipo de embalagem para laranja, para cada produtor considerado, podendo-se então escolher entre elas a mais viável economicamente. Para alimentar os dados pertinentes a essa planilha, foram contatados os mesmos produtores representativos de laranja-para-mesa, entrevistados inicialmente para definição da metodologia. Os dados utilizados no instrumental metodológico (Tabela 1), referentes a cada entrevistado, encontram-se anexos. Tais dados, associados à Tabela 1, permitiram identificar a embalagem mais viável para cada caso estudado.

Tabela 1. Planilha de custos ilustrativos de venda de laranja-de-mesa, em diferentes níveis de refugo e tipos de embalagens, 2003

\begin{tabular}{|c|c|c|c|c|c|}
\hline Refugo (\%) & $35,0 \%$ & $30,0 \%$ & $25,0 \%$ & $20,0 \%$ & $15,0 \%$ \\
\hline Perda (\%) & $2,00 \%$ & $2,00 \%$ & $2,00 \%$ & $2,00 \%$ & $2,00 \%$ \\
\hline Indústria (caixas de 40,8 kg) & 103,30 & 88,50 & 73,80 & 59,00 & 44,30 \\
\hline Clientes (supermercados ou atacadistas ou CEASAs) - $\mathrm{kg}$ de citros & 7.585 & 8.187 & 8.789 & 9.391 & 9.993 \\
\hline Total de laranjas enceradas ( $\mathrm{kg}$ ) & 10.306 & 10.547 & 10.788 & 11.029 & 11.269 \\
\hline \multicolumn{6}{|l|}{ Receitas } \\
\hline Total de Fruta para o Cliente (RS/caminhão truck) & $\mathrm{R} \$ 5.157,80$ & RS $5.567,16$ & $\mathrm{R} \$ 5.976,52$ & $\mathrm{R} \$ 6.385,88$ & RS $6.795,24$ \\
\hline Total de Fruta para a Indústria (RS/caminhão truck) & RS 826,40 & $\mathrm{R} \$ 708,00$ & RS 590,40 & R\$ 472,00 & R\$ 354,40 \\
\hline Frete médio Indústria ( $\mathrm{R} \$$ /caminhãotruck) & (RS 57,72) & $(\mathrm{R} \$ 49,45)$ & (R\$ 41,24) & (R\$32,97) & (R\$ 24,75) \\
\hline Total das receitas (RS/caminhão truck) & $\mathrm{R} \$ 5.926,48$ & RS $6.225,71$ & $\mathrm{R} \$ 6.525,68$ & $\mathrm{R} \$ 6.824,91$ & R\$ $7.124,89$ \\
\hline \multicolumn{6}{|l|}{ Despesas } \\
\hline Fruta (RS/caminhão truck) & $\mathrm{R} \$ 3.541,20$ & RS $3.541,20$ & $\mathrm{R} \$ 3.541,20$ & $\mathrm{R} \$ 3.541,20$ & $\operatorname{R} \$ 3.541,20$ \\
\hline Colheita (RS/caminhãotruck) & RS 501,67 & $\mathrm{R} \$ 501,67$ & RS 501,67 & R\$ 501,67 & R\$ 501,67 \\
\hline Frete Fazenda-Packing-House (R\$/caminhão truck) & R\$ 120,00 & $R \$ 120,00$ & RS 120,00 & R\$ 120,00 & R\$ 120,00 \\
\hline Despesas com uso de embalagens ( $\mathrm{R} \$$ /caminhãotruck) & RS 84,28 & RS 90,97 & $\mathrm{R} \$ 97,66$ & RS 104,34 & RS 111,03 \\
\hline Despesas com embalagens retornáveis perdidas ( $\mathrm{R} \$$ /caminhãotruck) & R\$ 8,43 & $\operatorname{R} \$ 9,10$ & R\$ 9,77 & $\mathrm{R} \$ 10,43$ & $\mathrm{R} \$ 11,10$ \\
\hline Despesas com carregamento/descarregamento ( $\mathrm{R} \$$ /caminhãotruck) & RS 0,00 & $\mathrm{R} \$ 0,00$ & R\$ 0,00 & RS 0,00 & $\mathrm{R} \$ 0,00$ \\
\hline Despesas com rótulos ( $\mathrm{R} \$$ /caminhão truck) & R\$ 28,09 & R\$ 30,32 & $\mathrm{R} \$ 32,55$ & $\mathrm{R} \$ 34,78$ & $\mathrm{R} \$ 37,01$ \\
\hline Beneficiamento (RS/caminhãotruck) & RS 602,00 & $\mathrm{R} \$ 602,00$ & RS 602,00 & R\$ 602,00 & R\$ 602,00 \\
\hline Intermediação (RS/caminhãotruck) & RS 103,16 & $\mathrm{R} \$ 111,34$ & RS 119,53 & RS 127,72 & RS 135,90 \\
\hline Cera (R\$/caminhão truck) & R\$ 32,85 & R\$ 33,62 & $\mathrm{R} \$ 34,39$ & $\mathrm{R} \$ 35,15$ & $\mathrm{R} \$ 35,92$ \\
\hline Frete Packing-House - Cliente (R\$/caminhãotruck) & RS 366,61 & $\mathrm{R} \$ 395,71$ & RS 424,80 & $R \$ 453,90$ & $\mathrm{R} \$ 483,00$ \\
\hline Despesas Diversas (R\$/caminhãotruck) & $\operatorname{R} \$ 37,93$ & $\mathrm{R} \$ 40,94$ & $\mathrm{R} \$ 43,95$ & $\mathrm{R} \$ 46,96$ & $\mathrm{R} \$ 49,97$ \\
\hline Despesas ICMS/frete+ Permissão trânsito (R\$/caminhãotruck) & RS 43,99 & RS 47,48 & $\mathrm{R} \$ 50,98$ & $R \$ 54,47$ & $\mathrm{R} \$ 57,96$ \\
\hline Despesas Bancárias (R\$/caminhãotruck) & R\$ 1,26 & R\$ 1,36 & RS 1,46 & RS 1,57 & $\mathrm{R} \$ 1,67$ \\
\hline Funrural (R\$/caminhãotruck) & R\$ 118,63 & $R \$ 128,04$ & RS 137,46 & R\$ 146,88 & R\$ 156,29 \\
\hline Desconto Financeiro (R\$/caminhãotruck) & R\$ 154,73 & $\mathrm{R} \$ 167,01$ & RS 179,30 & RS 191,58 & RS 203,86 \\
\hline Custo de oportunidade da embalagem (RS/caminhão truck) & R\$ 1,12 & $\mathrm{R} \$ 1,21$ & R\$ 1,30 & RS 1,39 & $\mathrm{R} \$ 1,48$ \\
\hline Perdas pelo uso da embalagem (R\$/caminhãotruck) & $\mathrm{R} \$ 515,78$ & $\mathrm{R} \$ 556,72$ & RS 597,65 & R\$ 638,59 & RS 679,52 \\
\hline Total das despesas (RS/caminhão truck) & $\mathrm{R} \$ 6.261,73$ & RS $6.378,69$ & $\mathrm{R} \$ 6.495,66$ & $\mathrm{R} \$ 6.612,62$ & RS $6.729,58$ \\
\hline Lucro (ou prejuízo) sem depreciação (R\$/caminhão truck) & (R\$335,26) & $(\mathrm{R} \$ 152,99)$ & $\mathrm{R} \$ 30,02$ & R\$212,29 & RS 395,30 \\
\hline Depreciação 8 anos (R\$/caminhão truck) & (RS 115,27) & $(\mathrm{R} \$ 115,27)$ & $(\mathrm{R} \$ 115,27)$ & (R\$ 115,27) & $(\mathrm{R} \$ 115,27)$ \\
\hline Lucro (ou prejuizo) líquido ( $\mathrm{R} \$$ /caminhãotruck) & (R\$ 450,53) & $(\mathrm{R} \$ 268,26)$ & $(\mathrm{R} \$ 85,25)$ & $\mathrm{R} \$ 97,02$ & RS 280,03 \\
\hline Valor do quilo de laranja destinada ao cliente, sem depreciação ( $\mathrm{R} \$ / \mathrm{kg})$ & RS 0,72 & RS 0,70 & RS 0,68 & RS 0,66 & $\mathrm{R} \$ 0,64$ \\
\hline Valor do quilo de laranja destinada ao cliente, com depreciação (RS/kg) & R\$ 0,74 & RS 0,71 & R\$ 0,69 & RS 0,67 & $\mathrm{R} \$ 0,65$ \\
\hline Valor de venda (RS/kg) & R\$ 0,68 & $\operatorname{R} \$ 0,68$ & $\operatorname{R} \$ 0,68$ & RS 0,68 & $\mathrm{R} \$ 0,68$ \\
\hline Lucro (prejuizo), sem depreciação (\%) & $(6,10) \%$ & $(2,67) \%$ & $0,50 \%$ & $3,44 \%$ & $6,18 \%$ \\
\hline Lucro (prejuizo), com depreciação (\%) & $(8,03) \%$ & $(4,60) \%$ & $(1,41) \%$ & $1,54 \%$ & $4,30 \%$ \\
\hline
\end{tabular}

Fonte: Fazendas Reunidas Raio de Sol; op. cit., p.4. 
$\mathrm{Na} 1^{\text {a }}$ coluna da Tabela 1 são apresentadas as rubricas necessárias para estruturar a avaliação final da viabilidade de uso dos diferentes tipos de embalagens considerados. A maior parte dessas rubricas (normalmente contabilizadas em $\mathrm{R} \$$ /caminhão truck ) diz respeito a despesas e receitas relacionadas com a comercialização da laranja-de-mesa e levando-se em consideração distintos níveis de refugo da fruta. Os valores apresentados para cada uma dessas rubricas estão relacionados com o resultado da venda de frutas do produtor para seu cliente e para a indústria, sendo descontado o valor do frete relativo ao trajeto "produtor - indústria". Nesse contexto, os valores referentes às despesas correspondem aos custos desde a colheita e beneficiamento, incluindo despesas com uso de embalagens, taxas de ICMS, FUNRURAL, despesas com carga e descarga, custos referentes às perdas proporcionadas pelo uso da embalagem considerada, frete do produtor até seu cliente e custos de oportunidade da embalagem em questão.

Da obtenção da receita total e da despesa total, descontando-se a depreciação referente ao maquinário de beneficiamento, obtém-se o "lucro com depreciação" (vide última linha da Tabela 1, em \%). Dessa forma, estabelecendo-se comparações com as porcentagens obtidas de lucro com depreciação, pôde-se observar para que nível máximo de refugo é considerada viável a venda de laranjas. Além disso, sob as mesmas condições de receitas e despesas obtidas nos processos de compra, beneficiamento e venda de uma carga de laranja de $12.040 \mathrm{~kg}$ equivalente a um caminhão truck (vinda da fazenda produtora), pôde-se analisar e estabelecer qual das embalagens é a mais viável economicamente, do ponto de vista de utilização, considerando-se diferentes tipos, sistemas de embalagens e custos envolvidos em cada um desses fatores.

Os dados apresentados na Tabela 1 são meramente ilustrativos. Podemse observar, na planilha, níveis de 15\%, 20\%, 25\%, 30\% e 35\% de refugo (frutas que apresentam manchas e moscas, que depreciam a qualidade do fruto para mesa), sendo que até $25 \%$ da carga total equivale ao nível médio considerado aceitável. Considera-se também que $2 \%$ da carga total equivale ao nível aceitável correspondente à perda de água por 
transpiração durante o transporte. É importante mencionar que os cinco valores porcentuais de níveis de refugo são considerados para cada tipo de embalagem. Logo, pode-se avaliar em quais níveis de refugo cada embalagem é mais viável economicamente, do ponto de vista de utilização, para determinados produtores.

Cada um dos produtores entrevistados constitui um estudo de caso, esta pesquisa é considerada, portanto, um estudo de multicasos. Para Triviños (1992), esse tipo de método científico permite ao pesquisador estudar dois ou mais casos, sem preocupação com a comparação dos resultados obtidos em cada um deles.

Yin (2001) relatou que o passo inicial para organizar um estudo de multicasos é a definição da teoria ou a caracterização do problema. Depois, parte-se para a apresentação dos casos selecionados e para definições dos indicadores de análise, que são de grande importância para o processo de coleta de dados e para o desenvolvimento da pesquisa, em que cada caso consiste de um estudo completo, com seus respectivos eventos relevantes e conclusões, apresentando, em determinadas situações, as causas pelas quais alguns fatos ocorreram e outros, não.

Dessa forma, este estudo visa detectar, por intermédio do uso da planilha Fazendas Reunidas Raio de Sol, op. cit., p.4 (apresentada na Tabela 1), qual embalagem é mais viável economicamente, do ponto de vista de utilização, em cada um dos casos (produtores entrevistados), dadas as respectivas condições específicas (vide anexo). Tal abordagem proporcionou, mediante um enfoque explicativo e analítico, o conhecimento de algumas características dos fenômenos relacionados com processos organizacionais de cada produtor, estabelecendo-se assim o evento ideal (tipo de embalagem) para cada caso. 


\subsection{Especificação dos dados}

Neste trabalho, dados os tipos de embalagens e casos estudados, tem-se que a embalagem de papelão é descartável, não retornando ao processo direto de uso de caixas, sendo, na maioria das vezes, reciclável. Ela é muito utilizada na destinação de frutas a mercados distantes, diretamente ao cliente, sem passar por CEASAs, e raramente é empregada no mercado interno para comercialização em mercados próximos (somente sob exigência do cliente).

A embalagem de madeira tipo " $\mathrm{M}$ " é retornável, tanto em percursos diretos até o varejo, a partir da fazenda produtora, como em percursos indiretos, em que os intermediários são as CEASAs ou a CEAGESP. Cabe ressaltar que o número de viagens de retorno dilui o preço pago pela embalagem, tornando seu uso atrativo ao produtor. No entanto, devese considerar uma perda de, aproximadamente, $10 \%$ de embalagens de madeira vazias retornadas.

Já as caixas plásticas, dentro do sistema reutilizável, podem ser consideradas como embalagens compradas ou de aluguel. Se pertencerem ao sistema "reutilizável comprada", essas embalagens são administradas pelo próprio produtor ou por algum responsável designado por ele, ocorrendo um nível quase nulo de perdas e extravios de embalagens retornadas. $\mathrm{O}$ fato de as caixas plásticas compradas apresentarem um preço de aquisição elevado faz com que os produtores comercializem as frutas diretamente do varejo, evitando os intermediários CEASAs e CEAGESP, que não possuem um sistema logístico adequado, o que pode vir a acarretar um grande número de embalagens extraviadas.

Se as caixas plásticas pertencerem ao sistema "reutilizável alugada", essas embalagens serão administradas por grandes supermercados (Pãode-Açúcar e Carrefour, por exemplo), os quais exigem que seus clientes utilizem caixas plásticas padronizadas de $20 \mathrm{~kg}$ e, para isso, efetuem um pagamento de aluguel pela utilização destas. 
Além dos fatores mencionados, de grande importância para a análise da viabilidade de embalagem para cada entrevistado, serão considerados três cenários para facilitar as comparações dos diferentes tipos de embalagens dentro de cada estudo de caso. Assim, por meio da Tabela 2, pode-se obter melhor compreensão de cada cenário considerado nesta pesquisa.

Tabela 2. Especificações de cada cenário considerado, 2003

\begin{tabular}{cll}
\hline Cenários & \multicolumn{1}{c}{ Mercado a ser atendido } & \multicolumn{1}{c}{ Embalagens possíveis } \\
\hline 1 & Supermercados de grandes redes & De plástico sob sistema aluguel \\
1 & Atacados, CEASAs ou CEAGESP & De madeira "M" \\
1 & Atacados, CEASAs ou CEAGESP & De papelão \\
1 & Atacados, CEASAs ou CEAGESP & De "plástico comprada" \\
\hline 2 & Supermercados de pequenas redes & De plástico sob sistema aluguel \\
2 & Atacados, CEASAs ou CEAGESP & De madeira "M" \\
2 & Atacados, CEASAs ou CEAGESP & De papelão \\
2 & Atacados, CEASAs ou CEAGESP & De "plástico comprada" \\
3 & Supermercados de pequenas redes & De plástico sob sistema aluguel \\
3 & Supermercados de pequenas redes & De madeira "M" \\
3 & Supermercados de pequenas redes & De papelão \\
3 & Supermercados de pequenas redes & De "plástico comprada" \\
\hline
\end{tabular}

Fonte: Dados de pesquisa.

A partir da ilustração da Tabela 2, tem-se:

Cenário 1: considera-se a utilização da embalagem de plástico sob o sistema de aluguel, quando o cliente é um supermercado pertencente a uma grande rede (taxa de desconto financeiro ${ }^{8}$ equivalente a $15 \%$ e o valor do aluguel da embalagem é dado por $\mathrm{R} \$ 4,50^{9}$ por embalagem). Além disso, consideram-se as utilizações das embalagens de papelão, de "plástico comprada" e de madeira "M", quando o cliente corresponde aos atacadistas, às CEASAs ou à CEAGESP (logo, a taxa de desconto financeiro, nesses casos, é nula).

\footnotetext{
${ }^{8}$ Taxa de desconto financeiro: estabelecida pelo supermercado (somente quando este for o comprador da carga), a qual é descontada no preço de compra das frutas. Essa taxa é exigida por supermercados a fim de repassar seus custos logísticos e custos provenientes de promoções realizadas aos seus consumidores, para os produtores (fornecedores de frutas).

${ }^{9}$ Valor referente a novembro de 2003.
} 
Cenário 2: considera-se o uso da embalagem de plástico sob o sistema de aluguel, quando o cliente é um supermercado pertencente a uma pequena rede (taxa de desconto financeiro equivalente a 3,5\%, e o valor do aluguel da embalagem é dado por $\mathrm{R} \$ 2,10^{10}$ por embalagem). Consideram-se, então, as utilizações das embalagens de papelão, de "plástico comprada" e de madeira "M", quando o cliente corresponde aos atacadistas, às CEASAs ou à CEAGESP (logo, a taxa de desconto financeiro, nesses casos, é nula).

Cenário 3: considera-se a utilização de todos os tipos de embalagens somente para clientes, como supermercados pertencentes às pequenas redes. Nesse caso, considera-se a taxa de desconto financeiro de 3,5\% como despesa para utilização de todas as embalagens, além da embalagem de plástico no sistema de aluguel.

A partir do conhecimento dos diferentes tipos de embalagens e respectivos sistemas considerados neste estudo de multicasos, composto por casos específicos de três produtores entrevistados, pretende-se esclarecer qual a embalagem é mais viável economicamente para cada um dos casos estudados, em cada cenário considerado.

\section{Resultados e discussão}

\subsection{Resultados e considerações sobre os entrevistados}

Foram documentadas as principais características dos três entrevistados (anexo) e comentados, a seguir, na Tabela 3, os resultados obtidos a partir da metodologia referente à planilha Fazendas Reunidas Raio de Sol, op. cit., p.4 (vide Tabela 1), conforme as especificações dos cenários considerados. A partir da análise do item "Lucro (ou prejuízo), com depreciação (\%)" correspondente à última linha da Tabela 1, pôde-se concluir qual embalagem, conforme os cenários considerados, poderia ser mais viável para cada entrevistado. A Tabela 3 mostra as embalagens

${ }^{10}$ Valor referente a novembro de 2003. 
viáveis e os respectivos sistemas mais viáveis de uso para cada produtor entrevistado nesta pesquisa, em cada situação ou cenário considerado.

Tabela 3 - Embalagens utilizadas ou recomendadas para cada produtor, 2003

\begin{tabular}{|c|c|c|c|}
\hline & Entrevistado 1 & Entrevistado 2 & Entrevistado 3 \\
\hline Cenário 1 & $\begin{array}{l}\text { Plástica } \\
\text { (comprada } \\
\text { retornável) }\end{array}$ & $\begin{array}{l}\text { Plástica } \\
\text { (comprada } \\
\text { retornável) }\end{array}$ & $\begin{array}{l}\text { Plástica } \\
\text { (comprada } \\
\text { retornável) }\end{array}$ \\
\hline Cenário 2 & $\begin{array}{l}\text { Plástica } \\
\text { (comprada } \\
\text { retornável) }\end{array}$ & $\begin{array}{l}\text { Plástica } \\
\text { (comprada } \\
\text { retornável) }\end{array}$ & $\begin{array}{l}\text { Plástica } \\
\text { (comprada } \\
\text { retornável) }\end{array}$ \\
\hline Cenário 3 & $\begin{array}{l}\text { Plástica } \\
\text { (comprada } \\
\text { retornável) }\end{array}$ & $\begin{array}{l}\text { Plástica } \\
\text { (comprada } \\
\text { retornável) }\end{array}$ & $\begin{array}{l}\text { Plástica } \\
\text { (comprada } \\
\text { retornável) }\end{array}$ \\
\hline Situação Atual & $\begin{array}{l}\text { Madeira } \\
\text { (retornável) }\end{array}$ & $\begin{array}{l}\text { Papelão } \\
\text { (descartável) }\end{array}$ & Plástica (aluguel) \\
\hline
\end{tabular}

Fonte: Dados de pesquisa.

O entrevistado " 1 " caracterizou-se pelo fato de vender as laranjas em caixas de madeira "M", destinadas às CEASAs e à CEAGESP. A partir da análise dos dados específicos desse produtor, observou-se que a embalagem de "plástico comprada" apresentou-se como a mais viável economicamente, do ponto de vista de utilização nos três cenários considerados, para todos os níveis de refugo (frutas que apresentam manchas e moscas, que depreciam a qualidade do fruto para mesa). Isso significa que, no primeiro cenário, esse produtor deveria vender suas laranjas a atacadistas ou às CEASAs preferencialmente, utilizando-se de embalagens de "plástico compradas", em vez de vendê-las aos clientes, supermercadistas pertencentes às grandes redes (que apresentam taxas de desconto financeiro de $15 \%$ e exigem o uso de embalagens de plástico, no sistema de aluguel). O segundo cenário também teria maior viabilidade, se o produtor utilizasse embalagem de "plástico comprada" para clientes dos tipos atacadista ou CEASAs, em vez de clientes supermercadistas; porém, nesse cenário os clientes supermercadistas pertencem às 
pequenas redes (que apresentam taxa de desconto financeiro equivalente a 3,5\% e não exigem necessariamente o uso da embalagem plástica sob o sistema de aluguel). Mesmo no terceiro cenário, em que apenas se considerou que o cliente corresponde a um supermercado pertencente a uma pequena rede, foi encontrada maior viabilidade econômica ao utilizar a embalagem de plástico comprada.

O entrevistado " 2 " destacou-se por vender suas frutas em embalagens de papelão a mercados distantes (localizados na região Nordeste), sendo de responsabilidade do cliente as despesas relativas ao frete correspondente a esse percurso. Nesse caso, qualquer um dos tipos de embalagens considerados neste estudo apresentou-se economicamente viável, sendo a embalagem de plástico comprada a mais viável em todos os cenários e em todos os níveis porcentuais de refugo. No segundo cenário, notou-se também que poderia haver maior viabilidade, se o produtor utilizasse embalagem de "plástico comprada" para clientes do tipo atacadista ou CEASAs, em vez de clientes supermercadistas pertencentes às pequenas redes. Já no terceiro cenário, em que o cliente correspondia a um supermercado pertencente a uma pequena rede, foi também constatada maior viabilidade econômica, ao utilizar a embalagem de "plástico comprada". Além disso, o cliente desse entrevistado localizase a uma distância de $1.970 \mathrm{~km}$ a partir do Packing-House, o que demandou a consideração de perdas proporcionadas pelo uso de embalagens de papelão (em razão da má ventilação interna) e de madeira (em virtude da falta de estabilidade de pilha e abrasão aos frutos).

O entrevistado " 3 ” era usuário da embalagem de plástico, no sistema de aluguel, e as fornecia a supermercados pertencentes ao grupo Pão-deAçúcar (considerado como grande rede supermercadista). A partir das simulações conduzidas, observou-se que a embalagem de "plástico comprada" apresentou-se como a mais viável economicamente, do ponto de vista de utilização nos três cenários considerados e em todos os níveis de refugo em questão. Com base nesses fatores, cabe ressaltar a importância da planilha Fazendas Reunidas Raio de Sol, op. cit., p.4, não apenas como instrumental de análise para obter qual embalagem é mais 
viável economicamente de uso para cada entrevistado, mas também como instrumental de formação do preço $(\mathrm{R} \$ / \mathrm{kg})$ da fruta a ser vendida ao cliente, de forma que o produtor venha a detectar a partir de que preço são notados lucros. Assim, por meio da Tabela 4, observa-se o preço $(\mathrm{R} \$ / \mathrm{kg})$ pelo qual deveriam ser vendidas as laranjas, conforme o entrevistado, para que se obtivessem lucros, em todos os níveis de refugo.

Tabela 4 - Preço do kg da fruta, nos cenários considerados, utilizandose determinadas embalagens, para obtenção de um valor a partir do qual se obtêm valores de lucro com depreciação em todos os níveis de refugo, para cada entrevistado, 2003

\begin{tabular}{clccc}
\hline Entrevistado & \multicolumn{1}{c}{ Embalagens } & $\begin{array}{c}\text { Cenário 1 } \\
(\mathrm{R} \$ / \mathrm{kg})\end{array}$ & $\begin{array}{c}\text { Cenário 2 } \\
(\mathrm{R} \$ / \mathrm{kg})\end{array}$ & $\begin{array}{c}\text { Cenário 3 } \\
(\mathrm{R} \$ / \mathrm{kg})\end{array}$ \\
\hline 1 & Papelão (descartável) & 0,68 & 0,68 & 0,70 \\
1 & Plástico (alugada) & 0,70 & - & - \\
2 & Papelão (descartável) & - & - & 0,57 \\
3 & Papelão (descartável) & 0,62 & 0,62 & 0,65 \\
3 & Plástico (alugada) & 0,64 & - & - \\
\hline
\end{tabular}

Fonte: Dados de pesquisa.

Nesse sentido, observou-se que, se o entrevistado "1", no cenário 1, desejasse utilizar as embalagens de papelão e de plástico, no sistema de aluguel, que até então havia dado prejuízos, deveria vender suas laranjas ao preço mínimo de $\mathrm{R} \$ 0,68 / \mathrm{kg}$ e ao preço de $\mathrm{R} \$ 0,70 / \mathrm{kg}$, respectivamente, para observar lucro em todos os níveis de refugo, contrariando a opção inicialmente estabelecida (que corresponde ao uso da embalagem de "plástico comprada" como a mais viável para o cenário 1). No cenário 2, ele deveria vender suas frutas ao preço de $\mathrm{R} \$ 0,68 / \mathrm{kg}$, utilizando-se a embalagem de papelão, para obter lucro em todos os níveis de refugo, se desejasse contrariar a opção estabelecida inicialmente ("plástico comprada"). Já no cenário 3, esse produtor deveria vender a laranja ao preço de $\mathrm{R} \$ 0,70 / \mathrm{kg}$, se desejasse utilizar a embalagem de papelão, contrariando a opção indicada inicialmente ("plástico comprada"), para obter um lucro em todos os níveis de refugo considerados.

No caso do entrevistado "2", somente seria observado prejuízo se fosse 
utilizada a embalagem de papelão, no cenário 3, para o nível de refugo equivalente a $35 \%$. Se mesmo assim fosse feita a opção de uso dessa embalagem nesse cenário, contrariando o tipo indicado inicialmente ("plástico comprada"), seriam constatados valores de lucro em todos os níveis de refugo considerado, se o produtor vendesse sua laranja ao preço de $\mathrm{R} \$ 0,57 / \mathrm{kg}$.

Para o entrevistado "3", observou-se, durante a análise dos resultados, que o uso da embalagem de papelão e de plástico sob o sistema de aluguel apresentou prejuízos de utilização, em todos os níveis de refugo no cenário 1 . Se, mesmo assim, esse entrevistado desejasse utilizar as embalagens de papelão e de plástico no sistema de aluguel, contrariando a embalagem inicialmente indicada como a mais viável ("plástico comprada"), ele deveria vender suas laranjas por R\$ 0,62/kg e R \$ 0,64/ $\mathrm{kg}$, respectivamente, para obter lucro em todos os níveis de refugo. No cenário 2, observou-se que apenas o uso da embalagem de papelão apresentou prejuízos de utilização. Se o entrevistado 3 insistisse na utilização dessa embalagem nesse cenário, contrariando a inicialmente estabelecida como a mais viável para esse cenário ("plástico comprada"), ele deveria vender sua fruta por $\mathrm{R} \$ 0,62 / \mathrm{kg}$, para que obtivesse lucro em todos os níveis de refugo. Observou-se também, no cenário 3, que o uso da embalagem de papelão foi a única alternativa que apresentou prejuízos de utilização. Assim, se esse produtor ainda desejasse utilizar essa embalagem, contrariando a opção iniciamente apresentada como a mais viável ("plástico comprada"), ele deveria vender o quilo da laranja por $\mathrm{R} \$ 0,65$, para obter o lucro em todos os níveis de refugo considerados.

\section{Conclusões}

Buscou-se, neste trabalho, no contexto de multicasos, analisar a viabilidade econômica da utilização de diferentes tipos de embalagens para laranjade-mesa, a partir do estudo de três casos referentes a produtores localizados no Estado de São Paulo. 
Conforme análises dos dados específicos de cada produtor, por intermédio da planilha Fazendas Reunidas Raio de Sol, op. cit., p.4, pôde-se concluir qual a embalagem mais adequada economicamente para cada caso, considerando-se os eventuais níveis de perdas proporcionados pelo uso das embalagens de papelão e das embalagens de madeira tipo "M".

Nesse sentido, os resultados apresentados e analisados neste trabalho permitem indicar que, genericamente, não há uma única embalagem mais viável economicamente, do ponto de vista de utilização. O que realmente se pode afirmar é que há embalagem mais viável economicamente para cada caso (ou produtor), dadas suas características específicas, como formas de negociações de frete com o cliente, pagamentos de taxas referentes ao transporte, níveis de perdas relativos ao uso de determinadas embalagens em distâncias longas, variações nos preços da fruta vendida ao cliente e à indústria, valores de preços referentes ao custo de beneficiamento, variações de custos referentes às embalagens utilizadas, despesas referentes à intermediação e variações de taxas relativas ao desconto financeiro (conforme o tipo de supermercado).

A partir dessas considerações, observou-se que a viabilidade de uso de cada tipo de embalagem está relacionada não apenas com o tipo de embalagem, mas também com o sistema utilizado (aluguel, retornável ou descartável), o que pode implicar despesas equivalentes às embalagens retornáveis perdidas nos casos de uso de embalagens de madeira e de "plástico compradas".

Cabe também relatar que o tipo de cliente influencia a análise da embalagem mais viável para os estudos de caso considerados. Se o cliente fosse um supermercado, deveriam ser consideradas as despesas referentes à taxa de desconto financeiro. Se o cliente fosse atacadista, CEASAs ou CEAGESP, essa taxa seria nula; porém, devem-se considerar despesas relativas às perdas de embalagens retornadas (para embalagens reutilizáveis), uma vez que esses clientes, normalmente, não apresentam condições logísticas adequadas para administração das caixas retornadas. 
Dessa forma, para uma avaliação mais concreta da embalagem mais viável para cada caso estudado, optou-se pela consideração dos fatores "tipos de clientes", "tipos de embalagens" e "tipos de sistemas" utilizados por produtor entrevistado, sob os níveis de refugo de 15\%, 20\%, 25\%, $30 \%$ e $35 \%$, em três cenários diferentes.

A planilha Fazendas Reunidas Raio de Sol, op. cit., p.4, até então não documentada na literatura, a partir deste estudo de multicasos, passa a ser formalmente reconhecida, o que permite a sua utilização em pesquisas acadêmicas e de ordem prática por parte de produtores de frutas, não obrigatoriamente de laranja. A partir disso, os produtores poderiam avaliar qual embalagem seria a mais viável economicamente para sua estrutura, permitindo também o estabelecimento do melhor preço da fruta para ser vendida ao cliente (e eventualmente à indústria), quando desejasse utilizar outras embalagens alternativas às inicialmente estabelecidas como as mais viáveis, dentro de cada cenário, observando lucros em todos os níveis de refugo. Provavelmente, a embalagem mais viável ao produtor poderia conferir um preço ao produto final mais viável ao consumidor.

\section{Referências bibliográficas}

IVANCKO, S.B. Escolha de embalagens para frutas e verduras. Agrianual 2002. Anuário da Agricultura Brasileira, p.40, 2002.

OLIVEIRA, C.L.; NEVES, M.F.; SCARE, R.F. Embalagens para alimentos com enfoque em marketing: projetos e tendências. In: NEVES, M.F.; CASTRO, L.T. Marketing e estratégia em agronegócios e alimentos. São Paulo: Atlas, 2003. cap.7, p.147-161.

TRIVIÑOS, N.S. Introdução à pesquisa em ciências sociais: a pesquisa qualitativa em educação. São Paulo: Atlas, 1992. 175p.

YIN, R.K. Estudo de caso: planejamento e métodos. Porto Alegre: Bookman, 2001.205p. 
Abstract - This current study aims to identify the most feasible type of packages for fresh oranges, produced and commercialized in the São Paulo state. In order to do so, three studies of specific cases were considered, under the context of multi cases. It was aimed to determine the cost of processing, packaging and transporting related to the orange commercialization aimed at customers such as wholesalers, supermarkets and Supplying Centers (CEASA's), from a Packing-House. The results presented and analyzed in this study allowed to indicate that, in general terms, there is no package more feasible economically speaking, considering its use. What was really observed was that there is a package that is more feasible for each producer considering his specific characteristics, such as: forms of freight negotiations with the customer, the payment of taxes related to transportation, loss levels related to the use of determined packages in long distances, variations of the fruit prices sold to the customer and to the industry, values related to the processing, arbitrage and taxes of financial discounts (according to the type of supermarket). Based on the spreadsheet the producer will be able to use a tool to help make decisions related not only to the most feasible package to be used, but also as an instrument in defining the best sale price for their fruit $(\mathrm{R} \$ / \mathrm{kg})$, from which profits can be forecasted in all levels of refusals.

Keywords: packaging, economic feasibility and orange.

\section{Anexos}

\section{Tabela 5 - Dados específicos do entrevistado "1".}

\section{Para carga de fruta correspondenete a um caminhão truck}

com capacidade média para $12.040 \mathrm{~kg}$

Produtor: Entrevistado 1 Data: 29/09/2003 Variedade: Laranja-Pera

Dados iniciais Valores

Preço da fruta vendida ao Cliente $(\mathrm{R} \$ / \mathrm{kg})$

Preço da fruta vendida para a Indústria ( $\mathrm{R} \$$ caixa de $40,8 \mathrm{~kg}$ )

Frete do caminhão para a Indústria (R \$/caminhão truck)

Distância média da Fazenda até a Indústria $(\mathrm{km})$

Preço da caixa de 40,8kg de laranja vinda da produção até o Packing-House (R \$/caixa de $40,8 \mathrm{~kg}$ )

Despesa com colheita das frutas na Fazenda (R $\$$ /caixa de 40,8 kg)

Frete do caminhão da Fazenda para o Packing-House (R \$caminhão truck) 
REVISTA DE ECONOMIA E AGRONEGÓCIO, VOL.3, No 1

Fonte: Dados de pesquisa 
Tabela 6 - Dados específicos do entrevistado "2".

\begin{tabular}{|c|c|c|c|}
\hline \multicolumn{3}{|c|}{$\begin{array}{l}\text { Para carga de fruta correspondente a um caminhão truck com capacidade } \\
\text { média para } 12.040 \mathrm{~kg}\end{array}$} & \\
\hline \multicolumn{3}{|l|}{ Dados iniciais } & Valores \\
\hline \multicolumn{3}{|c|}{ Preço da fruta vendida ao Cliente $(\mathrm{R} \$ / \mathrm{kg})$} & 0,55 \\
\hline \multicolumn{3}{|c|}{ Preço da fruta vendida para a Indústria ( $\$ /$ caixa de $40,8 \mathrm{~kg}$ ) } & 9,60 \\
\hline \multicolumn{3}{|c|}{ Frete do caminhão para a Indústria ( $\mathrm{R} \$$ /caminhão truck) } & 383,60 \\
\hline \multicolumn{3}{|c|}{ Distância média da Fazenda até a Indústria $(\mathrm{km})$} & 250 \\
\hline \multicolumn{3}{|c|}{ Preço da caixa de 40,8kg de laranja vinda da produção até o Packing-House } & 10,00 \\
\hline \multicolumn{3}{|c|}{ Despesa com colheita das frutas na Fazenda (R\$/caixa de $40,8 \mathrm{~kg}$ ) } & 1,25 \\
\hline \multicolumn{3}{|c|}{ Frete do caminhão da Fazenda para o Packing-House (R\$/caminhão truck) } & 206,57 \\
\hline \multicolumn{3}{|c|}{ Distância média da Fazenda até o Packing-House $(\mathrm{km})$} & 100 \\
\hline
\end{tabular}

\section{Embalagens}

Preço do aluguel da caixa plástica para supermercados ( $\mathrm{R} \$ /$ caixa de $20 \mathrm{~kg}$ ao mês)

Despesa com descarregamento na Central do Supermercado (R $\$$ caminhão truck)

Preço da caixa de Madeira "M" (R $\$$ /caixa nova)

Durabilidade da caixa Madeira "M" (número de viagens)

Preço da caixa plástica comprada ( $\mathrm{R} \$ /$ caixa nova de $27 \mathrm{~kg}$ )

Durabilidade da caixa plástica comprada (número de viagens)

Preço da caixa de Papelão (R $\$$ /caixa nova de $18 \mathrm{~kg}$ )

Perda de caixas retornáveis Madeira (\%)

Perda de caixas retornáveis Plásticas (\%)

\section{Demais despesas}

Beneficiamento: seleção, higienização das caixas retornáveis, cola ou grampo para caixa de papelão - $(\mathrm{R} \$ / \mathrm{kg})$

Intermediação: terceiros que vendem frutas do Packing-House aos Clientes (\% do total vendido destinada aos terceiros)

Preço do tambor (para $160000 \mathrm{~kg}$ de fruta) de cera (R $\$ /$ tambor)

Frete do Packing-House até cliente (R\$/caminhão truck)

Distância média do Packing-House até cliente (km)

Despesa: chapas, pedágio, refeição motorista e descarregamento no cliente

( $\mathrm{R} \$$ /caminhão truck)

Despesa com ICMS sobre o frete (R $\$$ caminhão truck) ou \% do ICMS sobre o frete

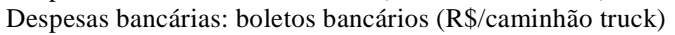

Taxa do Funrural (\%)

Taxa de desconto financeiro (\% do total da carga de um caminhão vendida aos supermercados)

\section{Estimativas de perdas de frutas proporcionadas pela utilização de cada embalagem (amassamento, má ventilação)}

Uso da caixa de Papelão (18 kg) em distâncias acima de $1000 \mathrm{~km}$ - (\%)

Uso da caixa de Papelão (18 kg) em distâncias abaixo de $1000 \mathrm{~km}-(\%)$

Uso da caixa de Madeira tipo "M" comprada retornável (27 kg) em distâncias acima de $1000 \mathrm{~km}-(\%)$

Uso da caixa de Madeira tipo "M" comprada retornável (27 kg) em distâncias abaixo de $1000 \mathrm{~km}-(\%)$

Uso da caixa de plástico em distâncias acima de $1000 \mathrm{~km}$ - (\%)

Uso da caixa de plástico em distâncias abaixo de $1000 \mathrm{~km}$ - (\%)

Fonte: Dados de pesquisa. 
Tabela 7 - Dados específicos do entrevistado “3”.

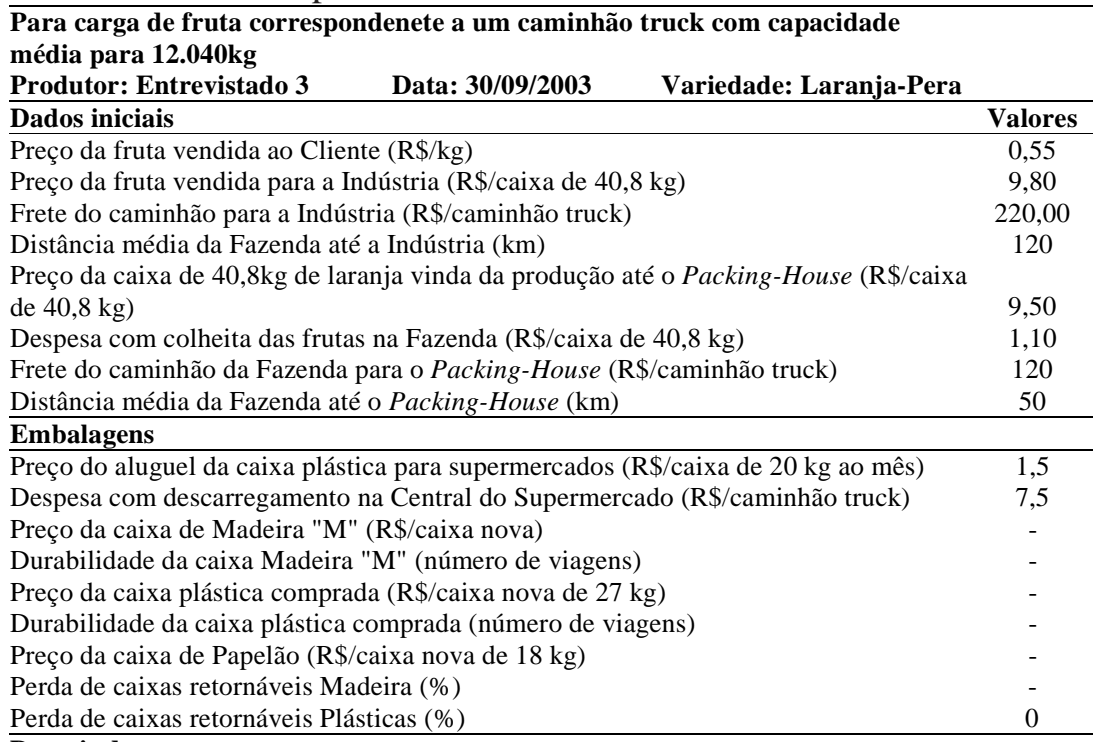

\section{Demais despesas}

Beneficiamento: seleção, higienização das caixas retornáveis, cola ou grampo

para caixa de papelão - $(\mathrm{R} \$ / \mathrm{kg})$

Intermediação: terceiros que vendem frutas do Packing-House aos Clientes

(\% do total vendido destinada aos terceiros)

Preço do tambor (para $160000 \mathrm{~kg}$ de fruta) de cera (R $\$ /$ tambor)

Frete do Packing-House até cliente (R $\$$ /caminhão truck)

Distância média do Packing-House até cliente $(\mathrm{km})$

Despesa: chapas, pedágio, refeição motorista e descarregamento no cliente

( $\mathrm{R} \$$ caminhão truck)

Despesa com ICMS sobre o frete (R $\$$ /caminhão truck) ou \% do ICMS sobre o frete

Despesas bancárias: boletos bancários ( $\mathrm{R} \$$ caminhão truck)

Taxa do Funrural (\%)

Taxa de desconto financeiro (\% do total da carga de um caminhão vendida aos supermercados)

Estimativas de perdas de frutas proporcionadas pela utilização de cada embalagem (amassamento, má ventilação)

Uso da caixa de Papelão (18 kg) em distâncias acima de $1000 \mathrm{~km}-(\%)$

Uso da caixa de Papelão (18 kg) em distâncias abaixo de $1000 \mathrm{~km}-(\%)$

Uso da caixa de Madeira tipo "M" comprada retornável (27 kg) em distâncias acima de $1000 \mathrm{~km}-(\%)$

Uso da caixa de Madeira tipo "M" comprada retornável (27 kg) em distâncias abaixo

de $1000 \mathrm{~km}-(\%)$

Uso da caixa de plástico em distâncias acima de $1000 \mathrm{~km}$ - (\%)

Uso da caixa de plástico em distâncias abaixo de $1000 \mathrm{~km}$ - (\%)

Fonte: Dados de pesquisa. 